\title{
DIGITALNA TRANSFORMACIJA HR MENADŽMENTA
}

\author{
Jelena Đorđević Boljanović ${ }^{1, ~ *}$, \\ Gordana Dobrijević1, \\ Filip Đoković, \\ Nataša Živojinović
}

\author{
1 Univerzitet Singidunum, \\ Beograd, Srbija \\ ${ }^{2}$ Služba za upravljanje kadrovima Vlade \\ Republike Srbije
}

Odgovorno lice:

Jelena Đorđević Boljanović

e-pošta:

jboljanovic@singidunum.ac.rs

\begin{abstract}
Rezime:
Proaktivnost funkcije menadžmenta ljudskih resursa (HRM) u 21. veku nužno zahteva i praćenje IT trendova koji neraskidivo povezuju menadžment ljudskih resursa i digitalizaciju. U navedenom smislu, tehnologija menja sve HR procese - od regrutovanja i zapošljavanja do upravljanja učinkom, a sve u cilju efikasnog sprovođenja poslovne strategije. Efikasni IT alati omogućavaju menadžerima ljudskih resursa da postanu strategijski poslovni partneri u pravom smislu reči, da stvore dodatu vrednost za poslovanje i unaprede organizacionu konkurentnost. Na putu ka digitalizaciji kao svakodnevnici, HR menadžerima su potrebna nova znanja i veštine, kao i potpuna podrška organizacije.
\end{abstract}

Ključne reči:

digitalna transformacija, ljudski resusrsi, informacione tehnologije, poslovna strategija.

\section{UVOD}

Informacione tehnologije uveliko menjaju savremeno poslovno okruženje. Otuda i potreba za promenom i modernizacijom funkcije menadžmenta ljudskih resursa u navedenom pravcu. U tom smislu ilustrativno je istraživanje kompanije Deloitte iz 2017. godine čiji rezultati pokazuju da je više od polovine kompanija već redizajniralo svoje HR programe u pravcu korišćenja digitalne tehnologije i mobilnih alata, 41\% HR timova aktivno kreira mobilne aplikacije za pružanje usluga menadžmenta ljudskih resursa, a 33\% koristi neku vrstu veštačke inteligencije za pružanje HR rešenja [1]. Internet portali, baze rezimea i biografija kandidata, online testiranja i procene samo su neke od metoda koje se koriste u procesu zapošljavanja, a koje omogućavaju unapređenje produktivnosti, uspešan odabir talenata i strategijski pristup regrutovanju i selekciji [2].

Zapravo, zadatak HR menadžera je da vode celokupnu organizaciju $\mathrm{u}$ tri pravca njene digitalizacije [3]. Prvi pravac je digitalizacija radne snage i stvaranje tzv. digitalnog DNK, a koje pretpostavlja uspostavljanje kulture inovacija, deljenja znanja i umrežavanje među talentima; drugi pravac je digitalizacija radnog mesta (stvaranje produktivnog i angažovanog radnog okruženja koje omogućava korišćenje savremenih komunikacionih alata kao što su Slack, Workplace Facebook, Microsoft Teams) i 
treći pravac je digitalizacija same funkcije menadžmenta ljudskih resursa. Možemo zaključiti da je u navedenom smislu zadatak HR menadžera mnogo širi od prostog uvođenja informacionih tehnologija u poslovno okruženje. Njihov zadatak je da pomognu da organizacija bude digitalna, ne samo da posluje digitalno [4].

\section{FAZE HR DIGITALIZACIJE}

Svestan promena koje pod uticajem informacionih tehnologija HR menadžment mora da pretrpi [5], autor Dejv Ulrih digitalizaciju HR funkcije posmatra kroz četiri faze [6]:

Prva faza: U kojoj meri se koristi tehnologija za pojednostavljenje administrativnog posla u HR sektoru? Mnoge kompanije kao što su Oracle ili SAP, nude posebne platforme, sisteme i softverske aplikacije za poslovna i HR rešenja koja obavljanje posla čine bržim, jeftinijim i lakšim.

Druga faza: U kojoj meri se koristi IT da bi se inovirale HR prakse? Svaka oblast upravljanja ljudskim resursima se unapređuje kroz tehnologiju. Tako na primer regrutovanje se može učiniti efikasnijim uz pomoć video intervjua i društvenih mreža, obuka zaposlenih uz pomoć online obuka, a planiranje sukcesije uz pomoć sistema za upravljanje karijerom. Oblast koja se odnosi na upravljanje performansama može biti inovirana automatizovanim evaluacijama i online sistemima za procenu učinka.

Treća faza: U kojoj meri se koristi tehnologija za pristup informacijama? Upravljanje informacijama je ključna za postizanje poslovnih rezultata. Pristup informacijama tradicionalno daje moć liderima zato što imaju više informacija od svojih zaposlenih. Danas, uz otvoreni pristup informacijama uz pomoć tehnologije, informacije se manje odnose na moć, a više na sposobnost donošenja boljih poslovnih odluka. HR odeljenja mogu uticati na poboljšanje upravljanja informacijama na tri načina. Prvo, HR treba da se zalaže za zapošljavanje stručnjaka iz oblasti upravljanja informacijama (big data analitičari, stručnjaci za društvene medije, cloud builders, app developers) Drugo, HR menadžeri mogu omogućiti da spoljašnje informacije dospeju u organizaciju radi donošenja boljih poslovnih odluka. Treće, informacije koje su osnova dobrih poslovnih rezultata mogu biti strukturirane i dostupne, ali i nestrukturirane koje se nalaze u iskustvima korisnika i zaposlenih i kojima HR menadžeri treba da pristupe kroz pažljivo posmatranje i analizu.
Četvrta faza: U kojoj meri se koristi tehnologija za stvaranje društvenih iskustava i veza? HR menadžeri mogu da koriste tehnologiju za izgradnju veza među ljudima koje stvaraju pozitivna društvena iskustva. Zaposleni danas mnogo više teže iskustvima koja će uticati na njihov lični identitet i blagostanje. Tehnologija poboljšava društvene veze ili stvaranjem mreža za rešavanje problema (gde ljudi rade na zajedničkim poslovnim problemima, korišćenjem društvenih mreža u kojima ljudi dele svakodnevne životne situacije) ili korišćenjem mreža u kojima se ljudi povezuju sa drugim ljudima koji dele njihove vrednosti. Ovde je potrebno naglasiti i neophodnost svakodnevnih interakcija ove vrste za mlade generacije.

\section{HR DIGITALIZACIJA KAO SVAKODNEVICA}

Drastična promena načina poslovanja utiče ne samo na organizaciju i njene klijente, već i na samu HR funkciju. U okruženju u kome kompanija poput Facebook-a nije samo društvena mreža, već je i najveća medijska kompanija iako sama ne kreira svoj sadržaj, u kome kompanija Alibaba posluje ne samo kao najveća e-commerce kompanija, već i finansijska i tehnološka kompanija koja briše granice među industrijama i u kojoj klijenti kupuju ili obavljaju svoje bankarske transakcije preko svojih mobilnih telefona svuda, u svakom trenutku, HR funkcija takođe mora da bude transformisana. U čemu se ogleda navedena transformacija i kako transformisana HR danas izgleda? Tri su glavne oblasti promena u menadžmentu ljudskih resursa - upravljanje performansama, pribavljanje talenata i HR analitika [7].

Promena HR funkcije u oblasti kontinuiranog upravljanja performansama podrazumeva uključivanje razvojnih planova, online procena performansi, gemifikacije i alata za upravljanje timom u svakodnevni posao. U oblasti privlačenja talenata budućnost je u brzim, sveobuhvatnim sistemima zapošljavanja koji će se fokusirati na poznavanje tehnologije, u veštačkoj inteligenciji koja će omogućiti iskustva poput virtuelnih obilazaka kancelarijskih i fabričkih lokacija, u avatarima koji će podržavati socijalizaciju i u sistemima za procenu potencijala koji će biti u mogućnosti da predvide uspeh kandidata sve do penzionisanja. Inovacije u oblasti HR analitike omogućiće analizu obrazaca komunikacije i performansi koji će predviđati ponašanje zaposlenih, usklađivati njihovo ponašanje i performanse sa potrebama za sukcesijom i predviđati potencijalne probleme u tim oblastima. 
Kako to izgleda u praksi [8]? Kompanija DuPont je, na primer, pokrenula veliki projekat da zameni, pojednostavi i kombinuje sve svoje HR sisteme i sisteme za učenje u jedan integrisani portal. Umesto da ponudi tradicionalnu „samouslužnu“ aplikaciju, kompanija je razvila moderniji interfejs koji poboljšava produktivnost. Telstra, jedna od najvećih telekomunikacionih kompanija u Australiji, koristi aplikaciju kako bi promenila prvo radno iskustvo svojih zaposlenih. Korišćenjem kritičkog razmišljanja, proučavanjem ponašanja i frustracija zaposlenih u prvoj godini rada, i poznavanjem karakteristika ličnosti, Telstra je razvila integrisani program socijalizacije koji je drastično poboljšao angažovanje zaposlenih i njihovo zadržavanje u kompaniji. Mnoge kompanije u praksi primenjuju alate koji im omogućavaju bržu i efikasniju digitalizaciju HR funkcije. Pod uticajem digitalizacije se menjaju i metode treninga i obuke zaposlenih. SmartUp je platforma za učenje u obliku mobilne aplikacije. Omogućava korisnicima da dobiju i dele znanje veoma brzo. Svaki zaposleni može kreirati onoliko zajednica za deljenje znanja koliko želi. Praksa pokazuje da veliki broj HR odeljenja danas uveliko povezuje tehnologiju i analitiku kako bi predvideli i procenili sve, od zadržavanja zaposlenih do strategija zapošljavanja. Tako npr. chatbot [9] omogućava kandidatima i zaposlenima automatizovane, personalizovane razgovore sa računarom. Zaposleni bi mogao da koristi chatbot da sazna koliko mu je ostalo dana za bolovanje ili odmor ili kakve procedure pokriva zdravstveno osiguranje kompanije. Takođe, kandidat za posao može odgovoriti na pitanja, kompletirati testove i pratiti status svoje prijave putem personalizovanog asistenta koji ima ime, lice i prijatno ponašanje. Naravno, sve ove funkcije su generisane kompjuterom.

Jedan od pionira u razvoju online učenja, ne samo u poslovnom okruženju, nego i na mnogim univerzitetima (Stanford, Harvard, MIT, Princeton), je baza online kurseva MOOC (Massive Open Online Courses). U sedmoj godini postojanja (2018), imala je već preko 100 miliona korisnika i 11.400 kurseva [10]. Nekoliko karakteristika ovih kurseva ih čine posebno prilagodljivima korporativnom učenju i razvoju: korisnici mogu da napreduju tempom koji im odgovara; učenje se ne odvija putem predavanja, nego putem istraživanja koje korisnik sam treba da sprovede; za mnoge kurseve zaposleni dobijaju sertifikate koji mogu da im pomognu u napredovanju [11]. Osim toga, MOOCs donose velike uštede kompanijama, jer ne moraju da kupuju ili kreiraju, a kasnije i održavaju poseban sistem online učenja [12].
Upotreba mobilnih telefona i aplikacija u menadžmentu ljudskih resursa još jedan su primer HR digitalizacije. Kvalitetne mobilne aplikacije omogućavaju produktivno korišćenje novih tehnologija, kao i menjanje stavova i praksi svih uključenih u HR procese. One su relativno jeftine, brzo se instaliraju, lako se koriste, mobilne su i stoga fleksibilne za upotrebu. One treba da budu jednostavne i fokusirane samo na jednu funkciju, na primer povratne informacije (feedback). Važno je da bude omogućeno merenje i analiza njihove upotrebe, tj. važno je znati koliko ljudi koristi određenu aplikaciju i na koji način [13]. Savremene mobilne aplikacije i alati poboljšavaju iskustvo zaposlenih, a organizaciju čine zaista digitalnom uz mogućnost mobilnog učenja, regrutovanja i zapošljavanja. Pomenućemo neke od njih [14]:

- Workday je HR alat koji pomaže organizacijama da integrišu zajedničke globalne prakse i istovremeno podrže jedinstvene potrebe. Ovaj alat pomaže u stvaranju kataloga radnih mesta, u upravljanju ugovorima o radu, uključujući probne periode, kolektivne ugovore i podatke iz ugovora. Takođe, omogućava upravljanje učinkom, pregled talenata i mesečno praćenje povratnih informacija na svom mobilnom telefonu.

- HireVue je alat koji radikalno menja proces zapošljavanja kandidata koji najbolje odgovaraju potrebama organizacije, i to sve preko "pametnih" telefona. On pruža menadžerima mogućnost da pregledaju strukturirane video zapise kandidata za posao, umesto preuranjenih intervjua licem u lice i da dobiju pregled podataka o kandidatu. Kandidati na ovaj način demonstriraju svoje sposobnosti, a ocenjuju se i rangiraju po HireVue algoritmima.

- Attendify [15] - za socijalizaciju. Razvijena je za pojednostavljivanje prijave i registracije, kao i poboljšanje celokupnog iskustva prilikom prisustva različitim događajima. U nekim kompanijama se koristi u fazi socijalizacije novih zaposlenih.

- Looop [16] - za učenje na radnom mestu. To je fleksibilna platforma za učenje, zasnovana na ideji da učenje treba da se desi kad i gde to zaposlenima odgovara, o temama koje su im potrebne.

- Vibe [17] - za ispitivanje posvećenosti zaposlenih bez uobičajenih anketa. Vibe postavlja pitanja korisnicima kako se osećaju povodom nagrađivanja, učenja ili komunikacije, a zaposleni odgovaraju slikom. Ovaj pristup omogućava brže odgovore, više intuitivne, jer slike više utiču na emotivni deo našeg mozga umesto racionalnog. 
- Smarp [18] - za poboljšanje komunikacije i posvećenosti zaposlenih. Predstavlja društvenu mrežu za deljenje relevantnog sadržaja zaposlenima.

- Next Jump [19] - za nagrađivanje zaposlenih. Omogućava zaposlenima pristup svim beneficijama koje nudi njihova kompanija i pomaže HR menadžerima da naprave najbolje programe nagrađivanja zaposlenih.

- Clear Review [20] - za merenje performansi zaposlenih. Ova aplikacija kombinuje povratne informacije u realnom vremenu, česte provere performansi (umesto jednom godišnje kao kod tradicionalnog pristupa) i ocene kolega.

- Facebook Workplace [21] - za komunikaciju i učenje. Predstavlja društvenu mrežu jedne organizacije, koja omogućava povezivanje preko $\mathrm{Fa}$ cebook grupa, audio i video pozive, učenje, testove i igre. Odvojena je od ličnih naloga korisnika na Facebook-u.

Uprkos sve većem prisustvu tehnologije u upravljanju ljudskim resusrsima, relativno malo istraživanja je bilo posvećeno njenoj efektivnosti, tj. u kojoj meri tehnologija omogućava organizacijama da ostvare ciljeve vezane za ljudske resurse. Kako smo analizirali u prethodnom delu članka, tehnologija je promenila način sprovođenja HR procesa (sakupljanje, čuvanje i deljenje informacija o kandidatima i zaposlenima). Ovde treba pomenuti i druge promene izazvane tehnologijom, npr. sve češći rad od kuće i saradnja u virtuelnim timovima, koji su promenili samu prirodu poslova i odnose među zaposlenima. Ne samo da je tehnologija omogućila interakciju između zaposlenih iz udaljenih geografskih područja, nego je i omogućila kompanijama da angažuju pojedince sa specijalizovanim znanjima iz bilo kojeg dela sveta.

Sa druge strane, postoji zabrinutost da uticaj nivoa poznavanja rada na računaru ili anksioznost pri izradi testova mogu biti naročito problematični za osetljive društvene grupe (stariji kandidati, manjine, ljudi slabijeg socioekonomskog statusa). Za ljude iz pomenutih društvenih grupa je manje verovatno da imaju pristup računaru i/ili internetu i često imaju niže nivoe informatičkih veština od većinskog dela stanovništva. U tom smislu, kompanije treba da obezbede, osim ranije navedenih savremenih metoda, $\mathrm{i}$ tradicionalne načine regrutovanja i selekcije [22].

\section{VEŠTINE HR MENADŽERA I DIGITALIZACIJA}

Najčešće se u spisku veština koje HR menadžeri treba da poseduju nalaze veština odnosa sa ljudima, veština donošenja odluka, veština liderstva i tehničke veštine. Tehničke veštine koje su danas zaista multidisciplinarne, u novije vreme je neophodno proširiti i na tzv. „data skills" koje bi podrazumevale veštinu upravljanja i korišćenja podataka. Ova veština je preduslov za rukovođenje procesom HR digitalizacije, što je svakako prioritetan zadatak HR menadžera. U tom smislu, organizacije treba da podrže svoje HR lidere u sledećim koracima [23]:

- Organizovanje internih partnerstava - u većini kompaniji druga odeljenja (npr. marketing ili finansije) najčešće već koriste podatke i tehnologiju na način koji HR može primeniti na vlastiti rad. Takva interna saradnja može ne samo da pomogne HR menadžerima da steknu nove veštine, već i da pomogne u podsticanju kulture koja se bazira na korišćenju podataka.

- Mapiranje i povezivanje HR analitike sa poslovnim rezultatima - HR menadžeri treba da znaju kako da povežu svoje podatke o zaposlenima sa rezultatima poslovanja. Ovaj proces mora početi prikupljanjem podataka o veštinama, sposobnostima i ponašanju zaposlenih, često kroz procene. Prikupljanjem podataka o veštinama i iskustvu zaposlenih i njihovim povezivanjem sa poslovnim rezultatima, HR može naglasiti ključne oblasti rizika i prilika za dalji razvoj kompanije.

- Razviti veštinu vizualizacije podataka - jednostavno prikupljanje podataka i analiza neće pomoći HR menadžerima da unaprede svoje napore ukoliko ne znaju kako da iskoriste te podatke, a kako bi uticali na druge. HR menadžeri bi trebalo da kreiraju npr. grafičke prezentacije podataka. Takođe, HR menadžeri treba da savladaju sofisticirane softverske programe kao što su Power BI, Tableau ili R Studio, koji pružaju vizuelni kontekst podacima.

- Implementirati modele planiranja liderstva - pored korišćenja podataka kako bi se istakli trenutni trendovi i nedostatak talenata, HR menadžeri bi trebalo da ih iskoriste za predviđanje budućih potreba za talentima, posebno za rukovodeće pozicije. HR menadžeri treba da koriste modele planiranja kako bi povezali dugoročni strateški plan sa 
liderima koji će ih implementirati. Modeli za planiranje liderstva omogućavaju HR menadžerima da kreiraju projekcije na osnovu podataka o broju potrebnih lidera, o veštinama koje će im biti potrebne i pozicijama na kojima će raditi. Ovi modeli mogu da uporede kvalitete i karaktersitike lidera sa onim što im je potrebno za obavljanje posla.

Korist razvoja navedenih veština se ogleda u mogućnosti HR menadžera da sugerišu korekcije u postavljanju prioriteta u sistemu zapošljavanja, razvoja zaposlenih i upravljanja učinkom.

\section{ZAKLJUČAK}

Digitalizacija omogućava pozicioniranje HR menadžera kao strategijskih poslovnih partnera koji u promenjivom poslovnom okruženju traže mogućnosti za nove poslovne izazove. $\mathrm{U}$ tom smislu, zadatak HR menadžera je ne da se pitaju kada će koristiti IT u svojim svakodnevnim aktivnostima, već kako će promeniti mentalni sklop svojih zaposlenih da bi se pripremili za budućnost koja je već tu. Digitalizovani HR procesi olakšavaju donošenje poslovnih odluka, efikasno procesuiranje informacija i znanja, pojednostavljivanje i ubrzavanje poslovnih procesa, a sve to omogućava ostvarivanje osnovnog cilja savremenog menadžmenta ljudskih resursa - privlačenje i zadržavanje zadovoljnih i motivisanih talenata koji su ključni za organizacioni uspeh i koji su optimalnom brzinom usmereni ka budućnosti.

Napomena: Ovaj rad je deo projekta Ministarstva prosvete, nauke i tehnološkog razvoja, broj 47028, pod nazivom "Unapređenje konkurentnosti Srbije u procesu pristupanja EU” za period od 2011-2019.

\section{LITERATURA}

[1] W. Perlman, „Modernizing HR Means Moving To Cloud-Based“' Integrated Solutions, 2017. dostupno na https://www.forbes.com/sites/forbestechcouncil/2017/06/26/modernizing-hr-means-moving-tocloud-based-integrated-solutions/\#7a47af96724b, preuzeto 29.5.2018.

[2] J. Đorđević Boljanović, „Menadžment ljudskih resursa“, Univerzitet Singidunum, Beograd, 2018, str. 288.

[3] E. Volini, P. Occean, M. Stephan, B. Walsh, „Digital HR: Platforms, people, and work “, 2017, Global Human Capital Trends, Deloitte, dostupno na https:// www2.deloitte. com/insights/us/en/focus/humancapital-trends/2017/digital-transformation-in-hr. $\mathrm{html}$, preuzeto 6.2.2019.
[4] E. Volini, P. Occean, M. Stephan, B. Walsh, „Digital HR: Platforms, people, and work“, 2017, Global Human Capital Trends, Deloitte, dostupno na https:// www2.deloitte. com/insights/us/en/focus/humancapital-trends/2017/digital-transformation-in-hr. html, preuzeto 6.2.2019.

[5] D. Ulrich, „HR Business Partner 2.0“, 2018., dostupno na https://www.hrdconnect.com/2018/08/21/ dave-ulrich-hr-business-partner-2-0/, preuzeto 6.2.2019.

[6] D. Ulrich, „Four Phases of Digital HR Transformation“, 2018., dostupno na http://blog.hr-congress. com/four-phases-of-digital-hr-transformation/, preuzeto 6.2.2019.

[7] G. Selke, P. B. Soule, „Translating the HR Digital Revolution to Everyday Work“, 2017., dostupno na https://www.hcminfosystems.com/resources/ whitepapers/translating-the-hr-digital-revolutionto-everyday-work-170711055258.pdf, preuzeto 21.2.2019.

[8] M. Stephan, E. Volini, S. Uzawa, „Digital HR revolution, not evolution", 2018., dostupno na https:// www2.deloitte.com/insights/us/en/focus/humancapital-trends/2016/digital-hr-technology-for-hrteams-services.html, preuzeto 21.2.2019.

[9] S. Milligan, „HR 2025: 7 Critical Strategies to Prepare for the Future of HR. To become a trusted workforce advisor, HR must focus on seven critical areas, including business strategy, analytics and, of course, people“, 2018., Dostupno na https:// www.shrm.org/hr-today/news/hr-magazine/1118/ pages/7-critical-strategies-to-prepare-for-the-future-of-hr.aspx, preuzeto 7.3.2019.

[10] Mooc, dostupno na http://mooc.org/, preuzeto 20.3.2019.

[11] D. M. Savino, "The Impact of MOOCs on Human Resource Training and Development", Journal of Higher Education Theory and Practice, vol. 14, No.3, 2014, pp.59-64, dostupno na http://www.nabusinesspress.com/JHETP/SavinoDM_Web14_3_. pdf, preuzeto 20.3.2019.

[12] Z. L. Berge, "Possiblities for MOOCs in Corporate Training and Development", Performance Improvement, vol. 54, No.10, doi: 10.1002/pfi

[13] L. Adams, „The HR Change Toolkit“. Bramley UK: Practical Inspiration Publishing, 2019.

[14] M. Monir Azzouzi, „6 Tools That Make HR \& Your Employees Truly Digital“", 2018., dostupno na https://www.maxis.com.my/en/business/businessblog/2016/08/6-tools-that-make-hr-and-your-employees-truly-digital.html, preuzeto 20.2.2019.

[15] Attendify, dostupno na https://attendify.com/, preuzeto 7.3.2019. 
[16] Loop, dostupno na https://www.looop.co/, preuzeto 7.3.2019.

[17] Vibe, dostupno na http://vibearound.com/\#vibefor-business, preuzeto 7.3.2019.

[18] Smarp, dostupno na https://smarp.com/, preuzeto 7.3.2019.

[19] Next Jump, dostupno na http://www.nextjump. com/, preuzeto 7.3.2019.

[20] Clear Review, dostupno na https://www.clearreview.com/, preuzeto 7.3.2019.

[21] Facebook Workplace, dostupno na https://www. facebook.com/workplace/chat-app?path=chat-app, preuzeto 7.3.2019.
[22] D. Stone, D. Deadrick, K. Lukaszewski, and R. Johnson, "The influence of technology on the future of Human Resource Management", Human Resource Management Review, vol. 25, pp. 216-231, June 2015. doi 10.1016/j.hrmr.2015.01.002.

[23] E. Sinar, R. L., Ray, A. L., Canwell, „HR Leaders Need Stronger Data Skills“, 2018., Harvard Business Review, dostupno na https://hbr.org/2018/10/ hr-leaders-need-stronger-data-skills, preuzeto 7.2.2019. 